\title{
Author Correction: Rapid fabrication of reinforced and cell-laden vascular grafts structurally inspired by human coronary arteries
}

Tamara L. Akentjew 1,2,3,4, Claudia Terraza1,2, Cristian Suazo ${ }^{1,2}$, Jekaterina Maksimcuka ${ }^{5}$, Camila A. Wilkens ${ }^{1,2,3}$, Francisco Vargas ${ }^{6}$, Gabriela Zavala ${ }^{1,2}$, Macarena Ocaña ${ }^{1,2}$, Javier Enrione ${ }^{7}$, Claudio M. García-Herrera (1) ${ }^{8}$, Loreto M. Valenzuela ${ }^{4,9,10}$, Jonny J. Blaker (1) ${ }^{11}$, Maroun Khoury ${ }^{1,2,3}$ \& Juan Pablo Acevedo1,2,3

Correction to: Nature Communications https://doi.org/10.1038/s41467-019-11090-3, published online 15 July 2019.

The original version of this Article contained an error in the spelling of the author Jekaterina Maksimcuka, which was incorrectly given as Jekaterina Maksimuck. This has now been corrected in both the PDF and HTML versions of the Article.

Additionally, the original PDF version of this Article contained an error in Figure $6 c$ in which a third stress-strain curve was erroneously shown. The correct version of Fig. $6 \mathrm{c}$ is:
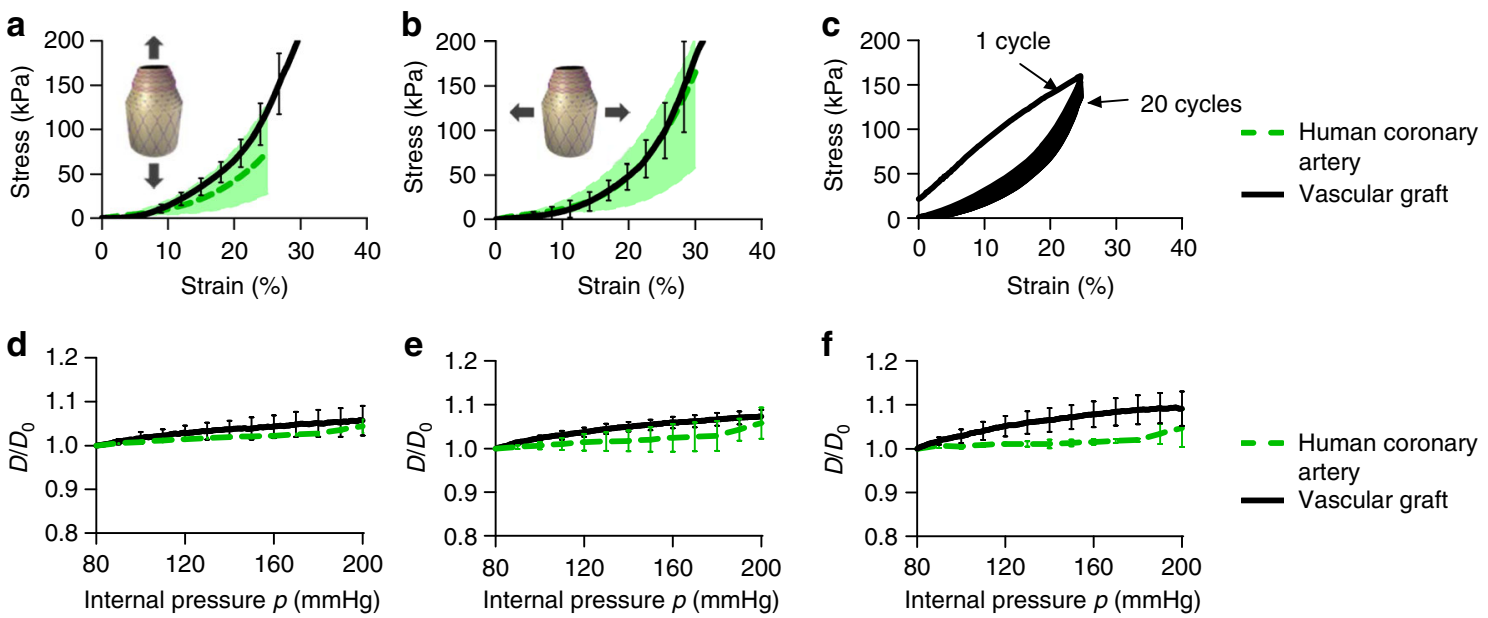

\footnotetext{
${ }^{1}$ Laboratory of Nano-Regenerative Medicine, Faculty of Medicine, Universidad de los Andes, San Carlos de Apoquindo 2200, Las Condes, Santiago 7620001 Chile. ${ }^{2}$ Cells for Cells, Avda. Plaza 2501, Las Condes, Santiago 7620157, Chile. ${ }^{3}$ Consorcio Regenero, Avda. Plaza 2501, Las Condes, Santiago 7620157, Chile. ${ }^{4}$ Department of Chemical and Bioprocess Engineering, School of Engineering, Pontificia Universidad Católica de Chile, Avda. Vicuña Mackenna 4860, Macul, Santiago 7820436, Chile. ${ }^{5}$ School of Materials, MSS Tower, The University of Manchester, Manchester M13 9PL, UK. ${ }^{6}$ Departamento de Cirugía Vascular y Endovascular, Pontificia Universidad Católica de Chile, Avda. Libertador Bernando O'Higgins 340, Santiago 8331150, Chile. ${ }^{7}$ Biopolymer Research and Engineering Lab (BiopREL), School of Nutrition and Dietetics, Faculty of Medicine, Universidad de los Andes, Avda. Plaza 2501, Las Condes, Santiago 7620157, Chile. ${ }^{8}$ Departmento de Ingeniería Mecánica, Universidad de Santiago de Chile, Avda. Libertador Bernando O'Higgins 3363, Estación Central, Santiago 9170022, Chile. ${ }^{9}$ Institute for Biological and Medical Engineering, Schools of Engineering, Medicine and Biological Sciences, Pontificia Universidad Católica de Chile, Libertador Bernando O'Higgins 340, Macul, Santiago 7820436, Chile. ${ }^{10}$ Center of Nanotechnology Research and Advanced Materials "CIEN -UC", Pontificia Universidad Católica de Chile, Avda. Libertador Bernando O'Higgins 340, Macul, Santiago 7820436, Chile. ${ }^{11}$ Bio-Active Materials Group, School of Materials, MSS Tower, The University of Manchester, Manchester M13 9PL, UK. Correspondence and requests for materials should be addressed to J.P.A. (email: jpacevedo@uandes.cl)
} 


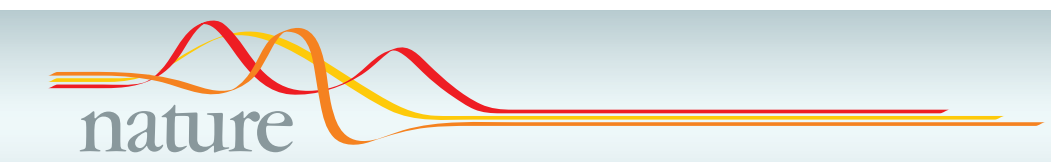

\section{COMMUNICATIONS}

which replaces the previous incorrect version:
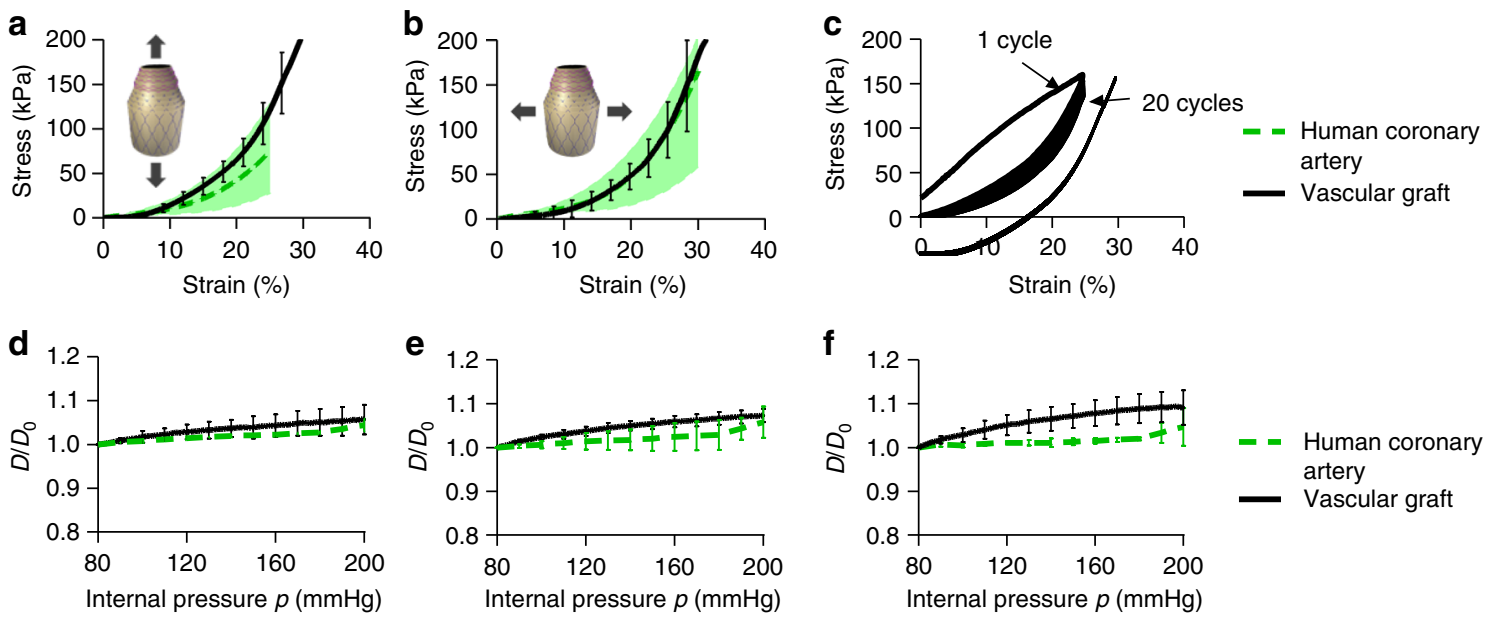

This has been corrected in the PDF version of the Article. The HTML version was correct from the time of publication.

Published online: 31 July 2019

(c) (1) Open Access This article is licensed under a Creative Commons Attribution 4.0 International License, which permits use, sharing, adaptation, distribution and reproduction in any medium or format, as long as you give appropriate credit to the original author(s) and the source, provide a link to the Creative Commons license, and indicate if changes were made. The images or other third party material in this article are included in the article's Creative Commons license, unless indicated otherwise in a credit line to the material. If material is not included in the article's Creative Commons license and your intended use is not permitted by statutory regulation or exceeds the permitted use, you will need to obtain permission directly from the copyright holder. To view a copy of this license, visit http://creativecommons.org/licenses/by/4.0/.

(c) The Author(s) 2019 